\title{
REUTILIZAÇÃO DOS RESÍDUOS DE MADEIRA DA CONFECÇÃO DE PALETES
}

\author{
REUSE OF WOOD WASTE FROM PALLET MANUFACTURING
}

Ingrid Daiane Platina - ingridplatina@ hotmail.com

André Luiz Oliveira - andre.oliveira@ fatectq.edu.br

Faculdade de Tecnologia de Taquaritinga (FATEC) - SP - Brasil

DOI: 10.31510/infa.v15i2.470

\section{RESUMO}

Desde o final da Revolução Industrial o homem tem buscado formas de compatibilizar desenvolvimento e preservação ambiental, um dos principais desafios da sociedade capitalista. A utilização de madeira no setor produtivo causa impactos ambientais que devem ser mitigados por meio de propostas que visem não somente o manejo correto desta matéria-prima, mas também processos de reaproveitamento, uma vez que se trata de uma estratégia não somente empresarial, mas necessária para a sociedade manter um nível minimamente satisfatório de qualidade ambiental. Neste contexto, o objetivo deste trabalho é evidenciar a necessidade de adoção de práticas que reduzam os impactos ambientais negativos gerados pelo desmatamento. Com vistas a ilustrar o trabalho e como metodologia de pesquisa foi realizado um estudo de caso em uma indústria de fabricação de paletes de madeira, que vem agregando em seu processo produtivo técnicas de reaproveitamento dos resíduos, como forma de mitigar os efeitos negativos do desmatamento. As conclusões destacam os benefícios oriundos da adoção de técnicas mais sustentáveis com relação ao manejo da madeira como fonte de matéria prima, além de técnicas para lidar de forma ambientalmente correta com as externalidades do processo.

Palavras-chave: Resíduos de madeira. Paletes. Sustentabilidade.

\begin{abstract}
Since the end of the Industrial Revolution, man has sought ways to compatible development and environmental preservation, one of the main challenges of capitalist society. The utilization of wood in the productive sector sake environmental impacts that must be mitigated through proposals that aim not only at the correct management of this raw material, but also reuse processes, since it wheter about one strategy not only business but necessary for society to maintaina a level minimally satisfactory of environmental quality. This context, the objective is this work is evidencing the need adoption practice that reduce the impacts negatives generated by deforestation. With vista to illustrate the work and as a research methodology a case study was carried out in a wood pallet manufacturing industry, which has beenevidenciar a necessidade de adoção de práticas que reduzam os impactos ambientais negativos gerados pelo desmatamento. adding in its productive process techniques of reuse if wastes, a how form to mitigate the negative effects of deforestation. The conclusions highlight the benefits oricing of from the adoption of more sustainable techniques with relation to the to management of wood as a source of raw material, beyond techniques to deal of form environmentally correct with process externalities.
\end{abstract}


Keywords: Residues of Wood. Pallets. Sustainability.

\title{
1 INTRODUÇÃO
}

De acordo com Machado (2011) o registro da exploração de madeira é uma das mais proeminentes e mais conhecidas formas de degradação e destruição da floresta, não obstante a verificação de melhoria nas técnicas de madeira e conscientização internacional, além de uma crescente preocupação com as florestas tropicais. Nota-se, porém, a continuidade de uma insustentável exploração madeireira de florestas húmidas tropicais, praticadas por empresas do setor privado e muitas vezes por sindicatos criminosos.

\begin{abstract}
As perdas de carbono na floresta amazônica pela degradação florestal representam até $40 \%$ das perdas pelo desmatamento. É o que revela artigo publicado por cientistas brasileiros e britânicos na revista Global Change Biology. O estudo, que coletou amostras de plantas e solos em 225 pontos da região e é o maior já realizado para as florestas tropicais degradadas, aponta a perda de carbono em florestas que passam por perturbações, como extração madeireira e fogo acidental (EMBRAPA, 2014, p. 02).
\end{abstract}

Existem, portanto, muitas razões para que as empresas exploradoras deste tipo de matéria prima redobrem sua atenção não somente com as imposições legais impostas pelo ordenamento jurídico ambiental brasileiro, mas também com as exigências de um mercado cada vez mais atento às questões éticas, sociais e ambientais.

Segundo reportagem publicada na Revista Exame (2018) a chamada "economia ecológica" (que surgiu nos anos 90) é um novo ramo da ciência dedicado a precificar o capital natural, uma vez que as florestas e seus ecossistemas prestam cerca de 17 serviços ambientais, conforme estudos desenvolvidos por um grupo de cientistas liderados pelo americano Robert Costanza, hoje pesquisador da Universidade de Vermont.

Ainda segundo os estudos desenvolvidos, tais serviços vão desde abastecimento de água e regulação climática ao fornecimento de alimentos, como peixes, frutas e castanhas, sendo que, para se calcular o valor de um ecossistema são consideradas inúmeras variáveis, tais como a área, a biodiversidade e o rendimento de commodities como a água e os peixes nos mercados internacionais.

Visando ilustrar as ações destinada a promover a política ambiental dos 3Rs, o estudo de caso contemplou as práticas realizadas na empresa PMA - Paletes Monte Alto, onde é possível verificar a busca de alternativas para a reutilização dos resíduos e ações que promovam 
a chamada "internalização das externalidades" no processo produtivo, com evidentes benefícios ambientais decorrentes.

\section{FUNDAMENTAÇÃO TEÓRICA}

\subsection{A exploração de madeira e impactos ambientais decorrentes}

Segundo Maisonnave (2018) de acordo com dados divulgados pelo governo do Estado do Mato Grosso, cerca de 61,7\% da exploração da madeira nesta unidade da Federação se encontra em áreas não autorizadas. $\mathrm{O}$ estudo leva em consideração o período entre junho de 2014 e outubro de 2015. Em comparação com a pesquisa anterior (2013/2014), constata-se que a área de exploração ilegal cresceu aproximadamente $27 \%$ em área onde o desmatamento é proibido por lei.

Herzog e Vieira (2018) citam um levantamento de dados do Prodes (sistema do governo que monitora com satélites o desmatamento da Amazônia), relatando que o andamento da destruição da floresta foi ampliado em cerca de 30\% (trinta por cento). No período compreendido entre agosto de 2015 a julho de 2016 foram aproximadamente 8.000 quilômetros quadrados de áreas de floresta extintos em um ano, o equivalente a uma área de 128 campos de futebol por hora, configurando-se como a maior extensão desmatada desde 2008 na Amazônia Legal, crimes praticados nos Estados do Pará, Mato Grosso, Rondônia e Amazonas, segundo os dados oficiais.

Os autores prosseguem afirmando que atualmente cerca de 1 milhão de hectares de matas da União na Amazônia estão sob permissão de empresas privadas que exploram comercialmente a madeira de florestas públicas por meio de contratos de manejo. Essas empresas, somente no ano de 2016, obtiveram cerca de 170000 metros cúbicos de madeira adicionados a outros contratos de concessão já assinados.

Ainda de acordo com Herzog e Vieira (2018) esse volume representa uma pequena fatia da demanda nacional (aproximadamente 5,5\%). Estima-se que $80 \%$ da madeira comercializada no Brasil seja ilegal ou "falsamente legal", através de manobras ilícitas efetuadas por madeireiras que conseguem burlar o sistema de controle do governo brasileiro.

Segundo Pena (2016) o chamado desmatamento (conhecido também como desflorestamento) consiste no método de extração total ou parcial da vegetação em uma área estabelecida, normalmente para fins econômicos no que tange à madeira das árvores e do solo. 


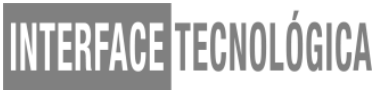

Hoje, os países em desenvolvimento são os que mais desmatam, pois, embora tentem realizar monitoramento, o desmatamento de suas florestas avança, fazendo com que o país ocupe o posto de segundo colocado no mundo em termos de desmatamento, sendo superado apenas pela Indonésia ao passo que seu sistema econômico cresça, pouco tempo atrás, o Brasil era o campeão mundial de desmatamento.

Para Derani (2007) há imenso prejuízo oriundo do desmatamento acelerado, prática que gera sérios danos ao equilíbrio ecológico, uma vez que, segundo dados da Organização das Nações Unidas (ONU), cerca de sete milhões de hectares/ano passam por este processo, gerando impactos das mais diversas ordens, tais como: esgotamento dos solos com a intensificação de processos de erosão e desertificação, a extinção ou degradação de rios e lagos, a ocorrência de desequilíbrios climáticos em razão da ausência das florestas que tinham como função gerar mais umidade do ar e absorver o calor atmosférico, dentre outros impactos.

A título de exemplificação, para a produção de 25 paletes de pinos seria necessária uma arvore adulta com cerca de 450 quilos, que devido ao seu porte, deixaria de produzir em um ano, em torno de 22 quilos de gás carbônico, além de oxigênio suficiente para a manutenção da qualidade do ar.

\subsection{Necessidades relacionadas ao reaproveitamento da madeira}

O reaproveitamento de materiais é uma das questões mais importantes no gerenciamento sustentável de resíduos. Uma dessas práticas consiste na reutilização dos resíduos da madeira, processo de grande valia paras questões ambientais, uma vez que integra a chamada "estratégia dos 3Rs (reduzir, reutilizar, reciclar).

A questão do reuso e redução na geração de resíduos constitui-se em uma das atividades chaves para enfrentar o desafio representado pelo destino final dos resíduos sólidos.

Uma das formas de reutilização dos resíduos de madeira diz respeito ao briquete e o cavaco. De acordo com dados do SEBRAE (2017) o briquite é um combustível sólido que pode ser usado de várias maneiras, sendo que, com seu manejo adequado é possível garantir seu ciclo, por meio de ações como o reflorestamento ou replantio, o que pode gerar uma economia muito grande se usado na substituição do carvão e da lenha. 
As serrarias brasileiras produzem grande quantidade de resíduos, porém, como não existe um mercado de comercialização para os mesmos, a compactação é uma opção para sua utilização energética, ainda necessitando de avaliações mais aprimoradas em relação à viabilidade econômica (BORGES et al, 1993).

Neste contexto, o governo tem um papel relevante no sentido de desenvolver políticas públicas para aproveitar sobras das indústrias madeireiras as reutilizando, por exemplo, como lenha, como uma das metas estabelecidas pelos projetos desenvolvidos pelo Instituto Brasileiro do Meio Ambiente e dos Recursos Naturais Renováveis (IBAMA, 2005).

Além dos benefícios ambientais, a reutilização de materiais é uma oportunidade de negócios, atividade geradora de emprego e renda, e subsidia estratégias de conscientização da população para o tema ambiental (IBGE, 2008).

De acordo com Oliveira (2016) os resíduos industriais de madeira se classificam em: serragem, sólidos de madeira, cascas, cepilho e outros que são originados desde seu transporte em forma de tora até à indústria, em seu manuseio, processamento e finalização do produto.

É possível identificar numerosos proveitos dos rejeitos da madeira, sendo um deles na própria indústria madeireira, onde uma parcela de seus resíduos é consumida para a produção de PMVA (produtos de maior valor agregado) que são o briquete, embalagem carvão e cabos.

A maioria das indústrias e empresas que utilizam a madeira como matéria prima, rejeitam a serragem, os paletes quebrados e pedaço de madeira (como tocos, ripas rachadas), deixando de observar que esses resíduos podem, em última análise, se constituírem em uma forma de redução dos custos de produção, ante seu potencial de reaproveitamento.

Outra forma de reaproveitamento da madeira diz respeito ao seu potencial de geração de energia, seja térmica, elétrica ou ambas (cogeração), por meio de sua combustão direta ou incineração, mediante um processo de gaseificação e na pirólise (produção de carvão). $O$ processo intermediário de aproveitamento energético é o de produção de briquete para subsequente combustão.

O briquete é um meio optativo para que o reaproveitamento da madeira, serragem ou cavaco, se convertam em substrato para uma reutilização de forma ecologicamente correta por meio dos processos de incineração e combustão direta, uma vez que parte das empresas e fábricas processadoras de madeira (dos segmentos de celulose, laminação/compensado, madeira serrada, papel, madeira, painéis reconstituídos, dentre outras) têm um processo fabril que requer a utilização de vapor. Como consequência imediata, podem se prover da cogeração de energia utilizando resíduos de madeira. (LIPPEL, 2018) 


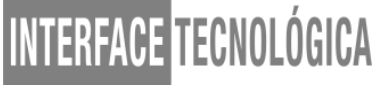

Alguns exemplos da utilização deste procedimento são abordados por Wiecheteck (2009), ressaltando que a gaseificação é uma opção pertinente de transformação energética de resíduos de madeira, como uma maneira econômica de produção de energia térmica ou elétrica, onde o gás de biomassa produzido em gaseificadores pode ser aplicado para diferentes finalidades, entre elas a queima de resíduos em caldeiras para criação de vapor; em secadores para secagem de peças de cerâmicas; em câmaras de combustão de motores de combustão interna e externa, turbinas a gás e células combustíveis.

Prossegue o autor exemplificando o tema com a chamada briquetagem como uma opção de matriz energética, reconhecendo que os resíduos de madeira podem ter duas finalidades principais: (I) Utilização como matéria prima para produtos de maior valor agregado (PMVA) ou (II) para fins energéticos, que se constitui na base do presente trabalho.

\subsection{O uso do briquete como alternativa de reaproveitamento.}

De acordo com dados do SEBRAE (2017) briquete é um biocombustível sólido, derivado de um processo de fabricação, gerado a partir da compactação de resíduos, lignocelulósicos de pressão e temperatura, desenvolvido por resíduos florestais ou agroindustriais, tornando-se, ao final deste processo, uma fonte de energia renovável com a mesma qualidade de qualquer outro tipo de lenha. O briquete de pó de serra é produzido por meio do procedimento de compactação mecânica, não sendo aplicado qualquer componente químico ou aglutinante no processo, em um processo em que todos os resíduos oriundos de serrarias e madeireiras (de qualquer tipo de árvore) são aproveitados.

Ainda segundo o SEBRAE (2017) "O uso de briquetes está associado à preservação ambiental, pois aproveita resíduo e substitui a lenha e o carvão vegetal sendo consumido pelas indústrias, comércio e residências".

Para que o briquete seja um produto competitivo no mercado, é oportuno que seu poder calorífico esteja dentro dos padrões desejados para as finalidades às quais ele se destina, seja em caldeiras, fornalhas ou na geração de eletricidade, pois o briquete tem uma densidade energética muito alta (GONÇALVES, 2009).

Com a reutilização desse material é possível se aproximar da solução de um problema ambiental, ao mesmo tempo em que se o processo se traduz em ganho financeiro para a empresa, uma vez que se determina o fim do desperdício das sobras de madeira (antes considerada "lixo"), mas que, com seu reaproveitamento, se converte em geração de energia. 
Segundo Stival (2007) como os briquetes são um produto produzido para amparar a indústria que precisa alimentar fornalhas e caldeiras, é possível identificar benefícios e vantagens do mesmo com relação à utilização da lenha, vantagens essas que vão além da simples ideia de reaproveitamento, passando por facilidades em relação ao seu transporte, manipulação e armazenamento.

Conclui o autor que seu formato cilíndrico padronizado reúne uma alta densidade de resíduos de madeira prensada (subproduto industrial), sem qualquer aditivo químico ou aglutinante, com grande poder calorífico. Além de proporcionar economia de energia elétrica, a nova lenha ecológica contribui diretamente para o controle do desmatamento e o fim da poluição motivadas pelas raspas de madeira antes jogadas no lixo.

A literatura específica aponta ainda outras vantagens dos briquetes:

- Menor custo direto e indireto;

- Reduz o impacto negativo sobre as florestas nativas para a retirada da lenha;

- Podem ser usados em caldeiras, lareiras, padarias, pizzarias, cerâmicas e outros;

- São fornecidos em embalagens padronizadas, uma tonelada de briquete substitui de 6 à $8 \mathrm{~m}^{3}$ de lenha;

- Poder calorífico de 2.5 vezes maior do que o da lenha 8comum apresentando regularidade térmica e maior temperatura da chama;

- Espaço de armazenagem reduzido, possibilitando assim a manutenção de estoques reguladores e de emergência;

- Devido à baixa umidade a temperatura se eleva rapidamente, produzindo menos fumaça, cinzas, e fuligem em relação à lenha;

- Não danifica a fornalha no manuseio de abastecimento;

- Menor índice de poluição pois é um combustível renovável. (REMADE, 2010, p12)

A briquetagem é composta na aglomeração de partículas finas por meio de pressão, com a ajuda ou não de um aglutinante, obtendo assim um produto não só compactado, porém com forma, tamanho e parâmetros mecânicos adequados. A Diminuição do seu volume, além dos benefícios tecnológicos, permite que materiais finos possam ser transportados e armazenados de forma mais econômica, culminando no entendimento de que o processo de briquetagem nada mais é do que a compactação de resíduos, por meio de aplicação de pressão a uma massa de partículas com ou sem adição de ligantes e com ou sem tratamento térmico posterior (SALAME, 1992).

\section{PROCEDIMENTOS METODOLÓGICOS}

A presente pesquisa possui caráter descritivo e exploratório e procura evidenciar uma questão totalmente voltada para um dos principais desafios da humanidade: a conciliação entre 


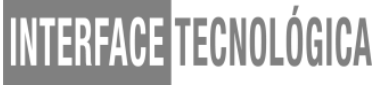

preservação ambiental e desenvolvimento. Para tanto, foi traçado um panorama geral a respeito dos benefícios oriundos do reaproveitamento de madeira, como forma de mitigar os danos ambientais oriundos do desmatamento.

De acordo com Gil (2006) o objetivo de uma pesquisa exploratória é compreender um assunto ainda pouco estudado. O estudo de caso, dentro de uma pesquisa exploratória, refere-se a uma situação, entidade ou conjunto de entidades que têm um mesmo comportamento ou são do mesmo perfil.

O estudo de caso demonstra a viabilidade de se agregar valor ambiental no processo de fabricação de paletes de madeira através da reutilização de seu subproduto como fonte alternativa de energia, captando valor não somente financeiro, mas ambiental e em última análise, social.

\section{RESULTADOS E DISCUSSÃO}

\subsection{Caracterização do universo empírico}

A empresa PMA - Paletes Monte Alto, universo empírico do presente estudo, surgiu em meados de 2008 na cidade de Monte Alto, Estado de São Paulo, sendo atualmente classificada como uma empresa familiar de pequeno porte que conta com 63 (sessenta e três) colaboradores e 04 quatro) sócios.

A empresa vem conquistando seu espaço no mercado ano a ano dentro de seu segmento de atuação, sendo que desde 2013, juntamente com outras 39 (trinta e nove) empresas do setor está credenciada pela ABRAS (Associação Brasileira de Supermercados).

A relevância dessa certificação reside no fato de que somente as empresas que integram o rol de certificadas por este órgão possuem permissão legal para a produção de paletes PBR (Palete Padrão Brasileiro), seguindo rigorosamente os padrões estabelecidos pela norma, atuando com destaque no que diz respeito à quantidade e diversidade de seu catálogo, o que a possibilita atender uma gama considerável de clientes.

Recentemente a PMA (Paletes Monte Alto) contratou uma empresa terceirizada e certificada para a realização do trabalho no tratamento de paletes, obedecendo a norma internacional (intitulada NIMF-15) que determina que toda e qualquer madeira exportada deve necessariamente passar por um processo denominado tratamento HT (Tratamento Térmico) ou 
MB (Fumigação com Brometo de Metila), procedimento inteiramente registrado pelo MAPA (Ministério da Agricultura, Pecuária e Abastecimento), no intuito de proporcionar a seus cliente produtos com qualidade no que se diz respeito a segmentos de estocagem e transporte de matérias já transformados ou ainda sob a forma de matéria prima.

A empresa tem como missão "criar soluções ambientalmente responsáveis, a um custo eficaz, satisfazendo as necessidades da movimentação de materiais".

\section{2 -Produção de Paletes e reaproveitamento de subprodutos.}

O gráfico 1 demonstra a produção de paletes somente na parte automatizada da empresa, tendo em vista a exigência do processo de automação por parte dos clientes.

Gráfico 1: Produção de paletes no processo automatizado (Janeiro a Agosto/2018).

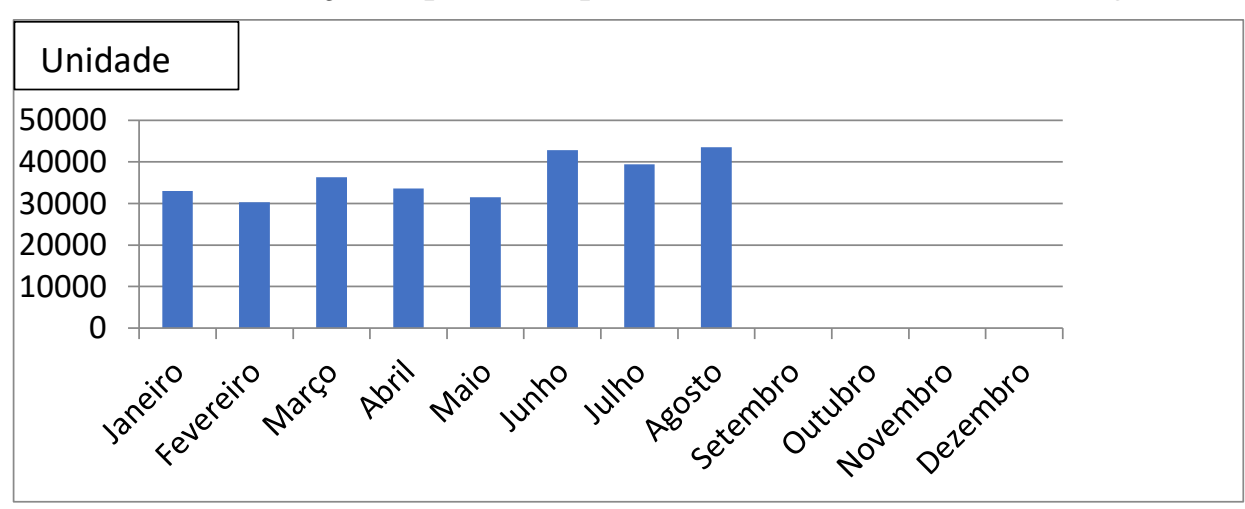

Fonte: Empresa Paletes Monte Alto (2018)

Nota-se que empresa atualmente compra em torno de $100 \mathrm{~m}^{3}$ por dia de madeira serrada e produz em torno de 45 mil paletes/mês, atingindo cerca de $80 \%$ de sua capacidade produtiva, com potencial para investimento futuro em máquinas que aumentariam a produção.

No intuito de evidenciar o comprometimento com seus clientes, a empresa PMA (Paletes Monte Alto) vem passando por diversas mudanças para se enquadrar nas normas que a habilitem a obter a certificação ISO 9001, como por exemplo, aquisição de madeiras de fornecedores que estejam autorizados expressamente pelo IBAMA, além de apresentar selo de madeira certificada e de reflorestamento.

Mesmo que o corte da madeira venha das serrarias, a empresa ainda produz grande quantidade de resíduos, em desconformidade no que diz respeito ao potencial de reaproveitamento para o uso da transformação de paletes. 


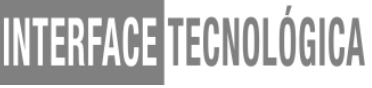

Após a revisão e modificação de processos internos, foram retirados da produção em média 6 bags de serragem, 5 bags de pontas de tocos e 3 bags de pedaços de ripas, ocasião em que a empresa optou pela destinação ambientalmente adequada (sustentável e econômica) desses resíduos, buscando parcerias com empresas de pequeno porte para este fim. Para melhor compreensão, "bags" são sacos destinados ao armazenamento de açúcar, grãos e serragem, dentre outros produtos.

A principal parceria firmada neste sentido proporciona um ganho ambiental considerável, pois através dessa comunhão de esforços, a Paletes Monte Alto se aliou a uma empresa que possui um veículo denominado "baguaceira" e um picador de madeira próprio, possibilitando a venda de um subproduto até então inutilizável (serragem e toco), material que será reprocessado e transformado em insumo que é utilizado como combustível em caldeira da empresa parceira.

Do ponto de vista financeiro os benefícios também são visíveis: em dias alternados a Paletes Monte Alto envia para a empresa parceira uma carreta com 85 bags, com valor fixado em $\mathrm{R} \$ 10,00$ (dez reais) cada um, sendo da parceira a responsabilidade da retirada e transporte desse material, antes tratado como lixo.

Importante reiterar que o processo de fabricação dos paletes envolve a retirada de madeira da floresta e uso de recursos naturais, como água e energia elétrica. Além disso, o transporte desse material depende do uso de combustíveis fósseis, como o óleo diesel ou gasolina que abastecem caminhões e carretas, daí a importância da reutilização, como forma de reduzir a magnitude dos impactos ambientais oriundos da extração de madeira, além de se evitar impactos indiretos oriundos de descartes inadequados.

Não obstante, os resíduos de madeira podem vir a se tornar materiais importantes nas mãos de artesão arquitetos e designers que conseguem transformá-los em novos móveis de decoração, produtos para casa, além de maquetes para área civil utilizando técnicas construtivas que demonstram grande preocupação com a qualidade final dos produtos, aliadas à consciência ecológica. A confecção de briquetes vem ganhando adeptos pela reciclagem de resíduos de madeira, constituindo-se também em um grande facilitador no quesito comodidade para o abastecimento de fornos e churrasqueiras nas grandes capitais, gerando valor agregado para as empresas e preservando o meio ambiente por meio de práticas ambientalmente corretas. 


\section{CONCLUSÃO}

O estudo realizado atingiu os objetivos inicialmente propostos uma vez que ficou evidenciada de forma clara e inequívoca a necessidade de adoção de métodos e técnicas que conduzam ao reaproveitamento da madeira como forma de implementação do conceito de sustentabilidade.

Os impactos ambientais oriundos do desmatamento, além de possuírem considerável potencial lesivo à saúde humana, se constituem em um dos principais obstáculos na busca pelo desenvolvimento sustentável, especialmente em virtude dos chamados "serviços ambientais" oferecidos pelas árvores.

A otimização relacionada à utilização dos briquetes como fonte de reaproveitamento de madeira se constitui em um passo decisivo para a implementação dos preceitos de sustentabilidade no processo de produção da empresa analisada.

Sob esta perspectiva, a empresa selecionada para o estudo de caso apresentou alternativas para a reutilização dos resíduos de madeira em seu processo de produção de paletes de forma automatizada, através de práticas que, se não possuem o condão de neutralizar completamente as fragilidades ambientais geradas, demonstram elevado potencial de mitigação de efeitos negativos, por meio de adoção de procedimentos, técnicas e ações destinadas à manutenção da qualidade ambiental.

\section{REFERÊNCIAS}

BORGES, A. S.; CINIGLIO, G.; BRITO, J. O. Considerações energéticas e econômicas sobre resíduos de madeira processada em serrarias. Silvicultura, São Paulo, v. 2, p. 603606, set. 1993. Acesso em: 26 maio

DERANI, C. Direito Ambiental Econômico. São Paulo: Max Limonad, 2007.

DERANI. Desmatamento e crescimento econômico no Brasil: uma análise da curva de Kuznets ambiental para a Amazônia legal. Disponível em: < http://www.scielo.br/scielo.php?script=sci_arttext\&pid=S0103-20032011000300008 Acesso em: 26 maio 2018.

EMBRAPA - Pesquisa aponta danos da exploração madeireira na Amazônia http://www.brasil.gov.br/noticias/educacao-e-ciencia/2014B/10/pesquisa-aponta-danos-daexploracao-madeireira-na-amazonia Acesso em: 26 maio 2018. 
Briquetes - Produção de lenha ecológica. Direção de Embrapa. [S.1.]: Youtube, 2014 A. P\&B. Disponível em: 〈https://youtu.be/Roq2Ka-2PRE〉. Acesso em: 26 maio 2018.

GIL, A. C. Métodos e técnicas de pesquisa social. São Paulo . Editora Atlas. 2006.

GONÇALVES, J. E. Energia de briquetes produzidos com rejeitos de resíduos sólidos urbanos e madeira de Eucalyptus grandis. Revista Brasileira de Engenharia Agrícola e Ambiental, Campina Grande, n. 5, v. 13, 660, set. 2009. Disponível em: https://repositorio.unesp.br/bitstream/handle/11449/71128/2-s2.0-

70349502601.pdf? sequence=1\&isAllowed=y. Acesso em 27 de maio de 2018.

HERZOG, A. L. VIEIRA, R. Brasil destrói 128 campos de futebol de floresta por hora. Disponível em: <https://exame.abril.com.br/revista-exame/brasil-destroi-128-campos-defutebol-de-flooresta-por-hora/>. Acesso em: 16 set. 2018.

IBAMA. Instituto brasileiro do meio ambiente e dos recursos naturais renováveis. Disponível em: < http://www.ibama.gov.br>. Acesso em 27 de maio de 2018.

IBGE. Indicadores de Desenvolvimento Sustentável. Disponível em: https://biblioteca.ibge.gov.br/visualizacao/livros/liv38797.pdf. Acesso em 27 de maio de 2018.

KANAYAMA, P. H. Minimização de Resíduos sólidos urbanos e Conservação de Energia -. Disponível em: < https://www.escavador.com/sobre/528256/paulo-helio-kanayama>. Acesso em 27 de maio de 2018.

LIPPEL. Briquetes de Biomassa e Carvão. 2018. Disponível em: <http://www.lippel.com.br/br/briquetes-de-biomassa-e-carvao.html>. Acesso em: 27 set. 2018.

MACHADO, P. A. L. M. Direito Ambiental brasileiro. 19. ed. São Paulo: Malheiros, 2011.

MAISONNAVE, Fabiano. Desmatamento Governo de MT ocultou dados de exploração ilegal de madeira. 2018. Disponível em: $<$ https://www1.folha.uol.com.br/ambiente/2018/04/governo-de-mt-ocultou-dados-deexploracao-ilegal-de-madeira.shtml>. Acesso em: 18 set. 2018.

OLIVEIRA, C. Biomassa, Resíduos Florestais e Industriais e Pellets de Madeira. 2016. Disponível em: <https://pt.linkedin.com/pulse/biomassa-res\%C3\%ADduos-florestais-eindustriais-pellets-de-celso-oliveira>. Acesso em: 25 jun. 2018. 
PENA. Desmatamento Disponível em: < https://brasilescola.uol.com.br/geografia/odesmatamento.htm>. Acesso em: 26 maio 2018.

REMADE. Briquetes são alternativas para aproveitamento energético da madeira.2010 Disponível em: <http://www.remade.com.br/br/revistadamadeira_materia.php?num=1479\&subject=B >. Acesso em: 10 jul. 2018.

REVIATA EXAME: Os serviços ambientais da floresta e o risco do desmatamento Disponível em: < https://exame.abril.com.br/economia/os-servicos-ambientais-da-floresta-e-o-risco-dodesmatamento-m0164749/A >. Acesso em 01 de outubro de 2018

SALAME, J. E. F. Estudo básico para briquetagem de carvão vegetal. Ouro Preto: Escola de Minas e Metalurgia, 1992. 19 p.

STIVAL, L. Briquetes. $2007 . \quad$ Disponível em: <https://monografias.brasilescola.uol.com.br/biologia/briquetes.htm>. Acesso em: 19 jun. 2018.

WIECHETECK, M. Aproveitamento de resíduos e subprodutos florestais, alternativas tecnológicas e propostas de políticas ao uso de resíduos florestais para fins energéticos. Apoio às Políticas Públicas na Área de Gestão e Controle Ambiental, Curitiba, p.9-12, 2009. Anual. 